\title{
Stress Intensity Factor of Reinforced Concrete Beams in Bending
}

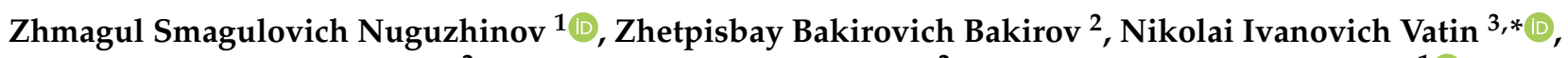 \\ Madi Zhetpisbaevich Bakirov ${ }^{2}$, Irina Alekseevna Kurokhtina ${ }^{2}$, Daniyar Tokanovich Tokanov ${ }^{1}$ (D) \\ and Omirkhan Khabidolda ${ }^{4,5}$
}

check for

updates

Citation: Nuguzhinov, Z.S.; Bakirov, Z.B.; Vatin, N.I.; Bakirov, M.Z.;

Kurokhtina, I.A.; Tokanov, D.T.;

Khabidolda, O. Stress Intensity Factor of Reinforced Concrete Beams in Bending. Buildings 2021, 11, 287. https://doi.org/10.3390/buildings 11070287

Academic Editor: Rita Bento

Received: 12 May 2021

Accepted: 29 June 2021

Published: 2 July 2021

Publisher's Note: MDPI stays neutral with regard to jurisdictional claims in published maps and institutional affiliations.

Copyright: (c) 2021 by the authors. Licensee MDPI, Basel, Switzerland. This article is an open access article distributed under the terms and conditions of the Creative Commons Attribution (CC BY) license (https:// creativecommons.org/licenses/by/ $4.0 /)$
1 Kazakhstan Multidisciplinary Institute of Reconstruction and Development Republican State Enterprise on the Right of Economic Use, Karaganda 100027, Kazakhstan; kazmirr@mail.ru (Z.S.N.); tokanov-daniyar@mail.ru (D.T.T.)

2 Mechanics Department, Building Materials and Technologies Department, Karaganda Technical University, Karaganda 100027, Kazakhstan; bakirov_50@mail.ru (Z.B.B.); madybacirov@rambler.ru (M.Z.B.); kurohtina.ira@mail.ru (I.A.K.)

3 Institute of Civil Engineering, Peter the Great Saint Petersburg Polytechnic University, 195251 Saint Petersburg, Russia

4 Mechanics Department, Al Farabi Kazakh National University, Almaty 050040, Kazakhstan; oka-kargtu@mail.ru

5 Algebra, Mathematical Logics and Geometry Department, Academician E.A. Buketov Karaganda University, Karaganda 100028, Kazakhstan

* Correspondence: vatin@mail.ru; Tel.: +7-9219643762

\begin{abstract}
The stress values at the crack tip in bending reinforced concrete beams are considered. The stress state is analytically determined with an initial and propagating crack. Equations of the equilibrium of a part of the beam cut along the crack line are compiled. These equations are reduced to a system of two nonlinear algebraic equations using the plane-sections hypothesis. The equations determine the stress zone's height and the nominal stress at the crack tip for a beam with an initial crack and the crack length. The rest of the stress state parameters are expressed regarding the zone stress height and the nominal stress or crack length. The same equation system determines the external moment starting from which the crack length increases. The analytical method for determining the stress intensity factor (SIF) with an initial and growing crack in bent reinforced concrete beams is proposed. The method is based on the assumption that the size of the stress concentration zone at the crack tip is determined by the equality of the nominal and local stresses at the end of this zone. The method determines the value of the external moment starting from which the crack length increases. The stress zone's size is determined by the coincidence of the local stress with the nominal stress. The same problem is solved in a three-dimensional formulation by the FE method, considering the stress field's peculiarities at the crack tip. The calculation results coincide with the analytical solutions.
\end{abstract}

Keywords: reinforced concrete; beam; bending; compressive side; crack; reinforcement; stress state; stress intensity factor

\section{Introduction}

Crack-like defects in reinforced concrete beams are very common [1,2]. They appear both at the manufacturing stage and the operational stage. These defects appear at the edge of the bending beam's tension side and propagate along the beam's cross-section towards the zero line. The appearance of cracks in bent members does not mean the exhaustion of its bearing capacity. However, cracks lead to an increase in internal forces in sections with a crack, which reduces the element's strength. In addition, the crack propagation increases the crack opening, increasing the corrosion of the reinforcement and reducing the structures' durability. A large data amount of empirical evidence has been accumulated 
on this topic. The stress-strain state of reinforced concrete beams with cracks, the crack opening width and crack propagation were studied in experiments [3-6].

Several monographs and articles were devoted to substantiating computational models and determining the stress-strain state of cracked beams. One paper [7] presents a critical overview of existing empirical analytical and numerical models for predicting the time to corrosion-induced cover cracking. In addition, a single comprehensive theory of structural behavior for reinforced concrete members subjected to bending, axial load, shear and torsion was proposed in a book [8]. The theory is based on a plasticity-oriented approach and is mainly oriented to frame structures for determining the failure load.

The crack sliding theory for beams with arbitrarily curved shear cracks and solutions for the implication of initial cracking on a load-carrying capacity was proposed in [9].

The problems of the fracture mechanics were formulated for the reinforced concrete structures in the presence of cracks for the second group of limit states [10]. They focus on the features of the predestruction zone. An approach for calculating reinforced concrete with allowance for physical nonlinearity, cracking processes, the bond of reinforcement with concrete and the effect of discontinuity were proposed based on the features of cutting a two-cantilever concrete member, including a crack. The stressed-strained state of the reinforced concrete element in the zone immediately adjacent to the crack was obtained.

One publication [11] was devoted to the stress-strain state of bending prestressed concrete beams with cracks. Three problems are successively solved: determining preliminary stresses in a reinforced concrete element, determining the moment of crack formation, determining the stress in a section with a crack. Analytical expressions have been obtained for determining preliminary stresses, the external bending moment at which a crack normal to the axis appears and the stress state parameters in the section with a crack, including the crack height. The stress intensity factor was not used in this analysis.

Tension stiffening relationships were proposed in [12] based on reinforced concrete beam tests. The method is based on the smeared crack approach. Average stress-strain relations for concrete in the tension state and compression state are determined from experimental moment-average strain and/or moment-curvature curves. Mainly, the smeared crack approach, which does not allow for bond-slip of reinforcing bars, would not give any crack widths.

In [13], an analytical analysis of reinforced concrete flexural members at the stage of stabilized cracking was carried out. The mean spacing between the primary cracks was established through the compatibility of the stress transfer and mean strain approaches. The crack spacing parameters were obtained by equating the mean strains of the tension reinforcement. The model is limited by assuming that one piece of a reinforced concrete beam with the length of mean crack spacing represents the averaged deformation behavior of the whole beam. It was shown that crack spacing is governed mainly by four geometrical parameters given in the order of significance: section height, reinforcement ratio, bar diameter and cover.

One of the main criteria for the limiting state of cracked reinforced concrete structures is the crack opening width. The crack opening width is determined in discrete crack models where the crack opening is associated with the bond-slip of reinforcing bars. The finite element method for discrete crack analysis, which does not require discrete crack elements, was developed [14,15]. Discrete bar elements model the reinforcing bars, and their bond-slip is allowed for using interface elements.

New engineering rules for crack width and space assessment of cracking patterns were proposed [16]. The opening of possible cracks produced at an early age due to restrained thermal or desiccation shrinkage, mechanical loadings during the execution phases and the crack opening due to further service loadings were considered.

A simple nonlinear finite element was formulated and validated in [7]. The finite element model was compared with analytical simplified formulated models of the nonlinear behavior of concrete without accounting for the objective location of reinforcing bars. 
In [17], a global-local post-treatment cracking model was used to quantify the cracking behavior of reinforced concrete structures. First, a continuous damage finite element model was used to perform a full resolution at a global scale. Then a reanalysis of the damaged zones was performed at the local scale with a discrete element model [18]. The steel reinforcement bars were also taken into account at the local scale. The comparison with experimental results confirmed the necessity of using a three-dimensional analysis of the crack pattern.

The numerical method was developed to predict concrete crack width induced by reinforcement corrosion [19]. A cohesive crack numerical formulated model for concrete was implemented to simulate crack initiation and propagation. The surface crack width is obtained as a function of service time. The numerical results were in good agreement with the analytical results, with an average difference of $4 \%$ within ten years.

Certain articles [20] were devoted to calculating crack resistance and the change in the stiffness of the beam and deflections during the formation of cracks. The stress-strain state is analyzed using the theory of elasticity and plasticity for a solid body. The resulting dependence makes it possible to find tangential stresses in the zone immediately adjacent to the crack.

There are still no generally accepted fracture mechanics criteria for assessing reinforced concrete structures' fracture toughness; such approaches were widely discussed. The paper [21] presented a two-dimension model based on nonlinear fracture mechanics for analyzing crack propagation in concrete. The fracture modes are pure tension or pure shear. The fracture is simulated through a discrete crack represented by the interface with a cohesive crack stress-separation relation. The relation is derived from the fracture criterion, together with a flow rule and a softening law. The model is used in the experimental studies' finite element simulations of different sizes of geometrically-similar three-point bend concrete specimens with mid-span and eccentric notches.

Under certain conditions, a crack in a beam can have an uneven development, estimated through fracture mechanics parameters. Most often, the stress intensity factor (SIF) was used. The SIF is the main parameter of linear fracture mechanics and is in good agreement with experimental data for brittle fractures. The stress intensity factor is used in linear fracture mechanics to describe stress fields at the crack tip. The definition itself arose from consideration of the problem of stress in a body with a crack. The stress field at the crack tips has a singularity of the form $1 / \sqrt{r}$, where $r$ is the distance from the crack tip to the point where the stress is considered [22]. In short, it is a measure of the singularity of stresses in the crack-tip vicinity.

The SIF was calculated by the finite element method (FEM) in a linear formulation [23]. The numerical analysis was performed on the reinforced concrete beam with an initial crack depth to assess the beam's damage with a different beam's width. Variations SIF for different beam widths and the force transmitted by the reinforcement bars to the concrete element with the change in the protective concrete layer's thickness was evaluated. Additionally, analytical studies were carried out on the reinforced concrete beam strengthened by the fiber-reinforced polymer. From the study, it can be concluded that the member's geometry plays a significant role in deciding the crack properties. Since the relationship between stress and deformation in concrete is not linear, nonlinearity introduces errors in SIF determination in a reinforced concrete element by the FE method, especially at high stresses. The development of a crack during bending of a reinforced concrete element is limited by the reinforcement in the tensioned zone and is blocked by the compression side's presence; therefore, the definition of SIF is different for the compression side and the tensioned side.

The critical stress intensity factor for various concrete grades and the influence of various factors on it were determined experimentally in [24-26].

Fracture mechanics parameters of fine-grained concrete with polypropylene fibers were studied in [24]. The critical SIF and the critical tip opening displacement were determined using the three-point bend test on beams with initial notches. The variations 
of SIF of the concrete beam versus type and volume fraction of synthetic fibers were received. A considerable increase in SIF was observed by increasing the fiber volume fraction in the concrete. The results showed that the pre-peak behavior of material was slightly affected by fibers to the cement matrix. The cement matrix properties dominated the deformation regime. The synthetic fibers also had a slight effect on the peak-load value and the strength properties. However, the post-peak behavior revealed an essential improvement in the energy-absorption characteristics compared to the reference concrete. All energy-absorption characteristics were strongly influenced by the content, type (length) and flexibility of the synthetic fibers.

One study [25] aimed to determine the influence of the steel fibers on the fracture parameters of concrete. The notched steel-fiber-reinforced concrete beams were subjected to a three-point bending test. The effects of the steel fiber volume fraction on the critical SIF, fracture energy, the deflection at failure, the critical crack mouth opening displacement and the critical crack tip opening displacement were studied. The addition of steel fiber to concrete can improve the fracture toughness of concrete. With the increase of steel fiber volume fraction, the critical SIF of steel-fiber-reinforced concrete specimens showed a good increasing trend. For every $0.5 \%$ increase in the fiber volume rate, the average increase of SIF was $33.7 \%$, and the average gain ratio was 2.275 .

Another study [26] aimed to determine the fracture parameters of steel fiber-reinforced notched geopolymer cement concrete beams with steel fiber reinforcement. The beams were submitted to bending tests. The fracture parameters obtained were crack mouth opening displacement, SIF, stored energy rate and J-integral. The results confirm the efficiency of steel fibers in decreasing crack propagation and preventing brittle fractures in composites. All the fracture parameters increased with fiber reinforcement, primarily by $0.5 \%$. Furthermore, post-peak behavior displayed higher bearing capacity, in addition to significant deformation up to a crack mouth opening displacement of $4 \mathrm{~mm}$. This behavior demonstrated the good fracture resistance obtained by geopolymer cement concrete with fibers.

A two-parameter fracture model was proposed to include nonlinear slow crack propagation in the concrete beam [27]. The critical stress intensity factor (SIF) was calculated at the tip of the propagated crack. Tests on notched concrete beam specimens showed the proposed fracture criteria to be size-independent. An accurate simulation of the experimentally observed tension and beam test results demonstrated the model's validity.

In [28], the definition of stress intensity factor based on physical dimensions different from the classical ones was considered by exploiting concepts of fractal geometry. First, the crack growth rate was expressed against the stress intensity factor range. Then, the size-dependent crack growth law was proposed.

Despite the many studies mentioned above, they pay little attention to the analytical determination of the stress state parameters of bending reinforced concrete beams with cracks, especially determining the length of the growing crack. There are also no publications devoted to determining the stress intensity factor in reinforced concrete beams with cracks.

In this article, the research object is a bending reinforced concrete beam with an initial and propagating crack. The subject of the study was the stress intensity factor at the crack tip. The aim of the study is a method for calculating the stress intensity factor at the crack tip in a reinforced concrete beam.

\section{Methods}

\subsection{Analytical Method}

An arbitrary design scheme of a bending reinforced concrete beam was considered. The support reactions were assumed to be found; the bending moments' epures were assumed to be known. It was assumed that the plane-sections hypothesis outside the crack zone is correct for calculating the stress state. The section method was used to determine the stress state in the beam. The beam was cut along the cross-section with a crack and 
the equilibrium equations of the cut-off part of the beam were compiled. The equilibrium equations express the condition that the sum of all forces' projection on the beam axis is zero. Therefore, the sum of all forces' moments relative to the section's transverse axis is zero when the beam is bent.

Two types of cracks were considered, for which the SIF must be determined:

(i) an initial crack that exists before the loads are applied,

(ii) a propagating crack that appears when external loads are applied.

The length of the initial crack was considered known. The initial length of this crack increases when the external moment exceeds a certain value of $M_{m}$. The moment $M_{m}$ causing crack propagation was determined from the equation of moments [29] by equating the nominal stress at the crack tip $\sigma_{m}$ to the tensile strength of concrete $R_{b t}$.

If the external moment is less than $M_{m}$, then the main unknowns in the equilibrium equations are the height of the compressive side of concrete beam $\mathrm{x}$ and the nominal stress at the crack tip $\sigma_{m}$ (Figure 1). If the external moment exceeds $M_{m}$, then $\sigma_{m}=R_{b t}$; and the second unknown is the new crack length, which enters the resolving equations through the length of the tension side above the crack $z_{p}$ (Figure 1).

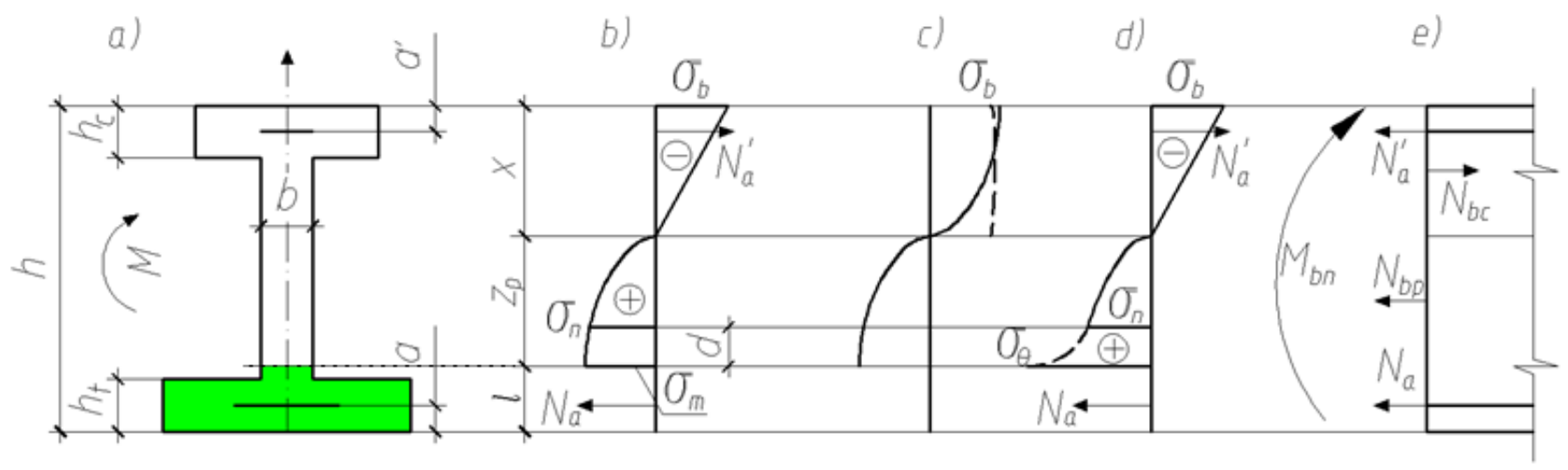

Figure 1. Scheme of stress distribution in the cross-section of a bending beam with the crack length $l$ and the height of the compression zone $x$ : (a) Cross-section of the beam; (b,c) Epures of nominal stresses in the beam section; (d) Epures of stress at the crack tip; (e) Forces acting in the section. The green color marks the crack zone.

The length of the propagating crack is unknown; it depends on the external moment. Therefore, in the case of a propagating crack, the main unknowns are the compressed zone's height $x$ and the size of the tension side above the crack. In this case, the moment $M_{m}$ takes on the meaning of the moment of crack formation. In subsequent calculations, it is assumed that $M_{m}$.

The reinforcement's adhesion to the concrete is disrupted in the crack zone; the reinforcement mainly perceives tensile forces. As a result, deformations and stresses change in reinforcement and concrete, and the height of the compressed zone above the crack changes. These changes are taken into account in the calculations by transforming the planar section law. The coefficients of non-uniformity in the crack zone $\psi_{s}, \psi_{b}$ are introduced to transform the epure of deformations into the linear epure $[8,30]$. These coefficients are equal to the ratios of the average deformations in the perturbed section $\varepsilon_{s m}$, $\varepsilon_{b m}$, to the deformations in the section with a crack $\varepsilon_{s}, \varepsilon_{b}$ :

$$
\psi_{s}=\varepsilon_{s m} / \varepsilon_{s}, \quad \psi_{b}=\varepsilon_{b m} / \varepsilon_{b},
$$

where the subindex $s$ refers to reinforcement and the subindex $b$ refers to concrete.

The crack is usually on the tension side. The rated stress at the crack tip is equal to the tensile strength of the concrete. The exponential law [31,32] was used to describe the nonlinear relationship between stress $\sigma$ and strain $\varepsilon$ in concrete

$$
\sigma=1.1 R_{b}\left[1-\exp \left(-0.9 \varepsilon E_{b} / R_{b}\right)\right],
$$


where $E_{b}$ is the modulus of elasticity and $R_{b}$ is the ultimate strength of concrete.

If the initial crack does not propagate at the beam where bending, then the maximum stress in the compression zone is much less than the limiting value. In this case, the relationship between stress and strain in the compressed zone can be assumed to be linear. When propagating cracks appear, this relationship is also described by expression (2).

The used analytical method is based on the standard equilibrium equations system. After solving the equilibrium equations system, all stress state parameters are determined: the maximum compressive stress in concrete $\sigma_{b}$, the stress in reinforcement $\sigma_{s}$, the crack length $l$ or the maximum tensile stress in concrete $\sigma_{m}$.

As already mentioned above, the stress intensity factor (SIF) measures the singularity of stresses in the crack-tip vicinity. The assumption was introduced to determine the SIF in this paper. It assumed that the longitudinal forces in the stress concentrations zone (from local stresses) are equal to the longitudinal forces from the nominal stresses in this zone.

The stress concentration zone size is determined as the zone where the local stress equals the nominal stress. The nominal stresses are taken from the solution of the equilibrium equations. The local stresses are taken from the plane problem of the elasticity theory for bodies with cracks.

\subsection{Numerical Calculation of the Stress Intensity Factor}

The SIF in a flexible reinforced concrete beam was calculated by the finite element method in a linear formulation based on a three-dimensional model. The SIF was determined from the displacement or stress field at the crack tip. ANSYS (Ansys, Inc., Canonsburg, PA, USA) was used in Interactive Workbench mode. The main stages of solving the problem were as follows.

In the Geometry menu, a geometric model of the beam was created and its settings were specified: coordinate system, material, dimensions. In the presence of several independent bodies in a geometric model, an additional Connections component appeared in the project tree, which allowed for setting up connections between surfaces. First, the beam was cut by two planes into four parts for the crack simulation, then bodies were glued along solid surfaces.

One plane was located vertically and perpendicularly to the beam axis in the place of the crack. The second plane was located horizontally at a distance of the crack length from the cracked beam's edge. First, the reinforcement was specified at one of the ends of the beam by specifying the center of gravity coordinates and the diameter of the reinforcing bar. Then the resulting circle was extruded to the length of the beam. Next, the materials of the obtained volumetric elements were specified, then the volumetric elements were glued along adjacent surfaces, except for the crack surface.

A tetrahedral volumetric finite element of the second-order Solid 187 with 10 nodes was used by default to SIF calculations. This element can take initial stresses into account using the ANSYS user subroutine USTRESS. The finite element size was chosen by gradually decreasing the size until the corresponding change in the oil recovery factor practically did not stop.

Boundary conditions and loads were set in the StaticStructural module using a named set of elements. In addition, the FractureTool option was specified to display SIF values at selected points of the crack front.

\section{Results and Discussion}

\subsection{Analytical Determination of the Stress State}

Pure bending of a reinforced concrete beam with two flanges with prestressed lower reinforcement and a transverse vertical crack was considered (Figure 1a). Figure 2 shows the general view of a beam with a crack. 


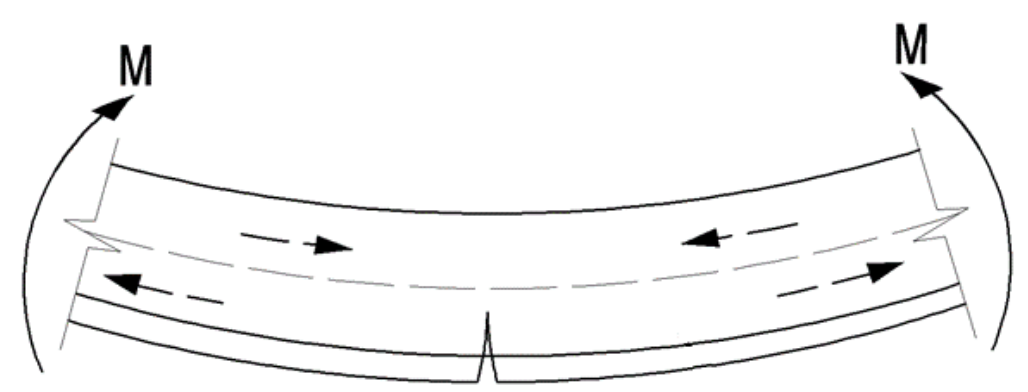

Figure 2. General view of a bent beam with a crack.

The following designations have been introduced:

$A_{c t}, A_{c}$ are the areas of overhangs of the shelves in the stretched and compressed zone; $h_{t}, h_{c}$ are the thicknesses of the shelves in the stretched and compressed zone;

$a, a^{\prime}$ are the thicknesses of the concrete cover in the tensioned and compressed zone; $A_{s}, A_{s}^{\prime}$ are the areas of reinforcement in the tensioned and compressed zone;

$N_{a}, N_{a}^{\prime}$ are the internal forces in the reinforcement of the tensioned and compressed zone.

Two cases are analyzed:

(i) The rated stress at the crack tip $\sigma_{m}$ is less than or equal to the concrete's ultimate tensile strength $R_{b t}$, and the crack length does not increase.

(ii) The rated stress at the crack tip $\sigma_{m}$ exceeds the concrete's tensile strength $R_{b t}$, increasing the initial crack length $l$.

First, an initial non-propagating crack $\left(M<M_{m}\right)$ is considered. Then, the beam is cut with a section through the crack. Considering the above-accepted assumptions, the stress epure in this section takes the form shown in Figure $1 b$.

The main unknown variables of the problem are the tensile stress at the crack tip $\sigma_{m}$ and the height of the compression zone $x$. Dimensionless stress at the crack tip $c$ and a dimensionless parameter $y$ are introduced

$$
c=\sigma_{m} / 1.1 R_{b t}, \quad y=-\ln (1-c)
$$

for the subsequent writing of the equilibrium equations. Then the deformation at the crack tip is determined by the expression

$$
\varepsilon_{m}=1.1 y R_{b t} / E_{b} .
$$

The deformation and stress at the edge of the compressed zone, taking into account the flat cross-section hypothesis, are

$$
\varepsilon_{b}=\varepsilon_{m} x / z_{p}, \quad \sigma_{b}=E_{b} \varepsilon_{b}=1.1 y R_{b t} x / z_{p},
$$

where $z_{p}$ is the height of the tension zone.

Taking into account the previously introduced coefficients of non-uniformity in the crack zone (1), the deformation and stresses in the reinforcement are equal:

$$
\begin{aligned}
& \varepsilon_{s}=\varepsilon_{m} \psi_{b s}(h-a-x) / z_{p}, \\
& \sigma_{s}=E_{s} \varepsilon_{s}=1.1 y R_{b t} \alpha \psi_{b s}(h-a-x) / z_{p}, \\
& \sigma^{\prime}{ }_{s}=\sigma_{s p}^{\prime}-E_{s} \varepsilon^{\prime}{ }_{s}=\sigma_{s p}^{\prime}-1.1 \alpha y R_{b t}\left(x-a^{\prime}\right) / z_{p},
\end{aligned}
$$

where $\alpha$ is the ratio of the moduli of elasticity of reinforcement and concrete; $\psi_{b s}=\psi_{b} / \psi_{s}$; $\sigma_{s p}^{\prime}$ is a prestress in the reinforcement of the compression zone.

The tensile stress at a distance $z$ from the zero line, taking into account (3) and the hypothesis of flat sections, has the form

$$
\sigma=1.1 R_{b t}\left[1-\exp \left(-y z / z_{p}\right)\right]
$$


The resultant internal forces in the tension side $N_{p}$, the moment of internal forces relative to the zero line $M_{p o}$ and the moment about the central axis $M_{p c}$ are determined by integration over the height of the stretched zone as:

$$
\begin{gathered}
N_{p}=n b \sigma_{m} z_{p}, \\
M_{p o}=m \sigma_{m} b z_{p}^{2} \\
M_{p c}=M_{p o}-N_{p}(h / 2-x),
\end{gathered}
$$

where $n=1 / c-1 / y, m=\left[0.5+(1-c)(1+y) / y^{2}-1 / y^{2}\right] / c$.

The equilibrium equations are as follows.

(i) The equilibrium equation of the beam's cut-off part in the form of the sum of the projection of forces on the beam axis is as follows:

$$
N_{p}+\sigma_{s} A_{s}-\sigma_{b} b x / 2+\sigma_{s}^{\prime} A_{s}^{\prime}-\sigma_{b} A_{c}\left(x-h_{c} / 2\right) / x=0 .
$$

(ii) The equilibrium equation in the form of the sum of the moments of all forces relative to the central axis of concrete has the form

$$
\begin{aligned}
& M_{p c}+\sigma_{s} A_{s}(h / 2-a)+0.5 \sigma_{b} b x(h / 2-x / 3)+\sigma_{b} A_{c}\left(x-h_{c} / 2\right)\left(h-h_{c}\right) / 2 x- \\
& -\sigma_{s}^{\prime} A_{s}^{\prime}\left(h / 2-a^{\prime}\right)+1.1 y \alpha R_{b t} A_{s}^{\prime}\left(x-a^{\prime}\right)\left(h / 2-a^{\prime}\right) / z_{p}=M_{b n} .
\end{aligned}
$$

For the case of reinforcement in a tension side without prestressing, the external moment is equal to the bending moment in the section with a crack.

For the case of prestressed reinforcement on the tension side, the stress arises after the moment of the external forces $M$ exceeds the moment of the pre-tensioning force. Then in this equation, the total external moment will be equal to

$$
M_{b n}=M-\sigma_{s p} A_{s}(h / 2-a) .
$$

Equilibrium Equations (9) and (10) are common for all reinforced concrete elements with and without prestressing, with different sectional shapes: I-beams, T-beams, rectangular. For T-beams, the area of overhang $\left(A_{c}\right.$ or $\left.A_{c t}\right)$ equals zero. For rectangular beams, the areas of both overhangs are zero. In order to obtain explicit design relationships, we will carry out a further solution for the most common case of a rectangular section with reinforcement on the tension side.

Next, the following dimensionless parameters are introduced:

$$
\begin{gathered}
\xi=x / h, \quad z=l / h, \\
\lambda=z_{p} / h=1-z-\xi, \\
\bar{h}=(h-a) / h, \\
\mu=A_{s} / b h .
\end{gathered}
$$

Then, taking into account expressions (5) and (6) for $\sigma_{b}$ and $\sigma_{s}$, equilibrium Equations (9) and (10) can be written in the dimensionless form:

$$
\begin{gathered}
n c \lambda^{2}-0.5 y \xi^{2}+y \alpha \mu \psi_{b s}(\bar{h}-\xi)=0 . \\
L=M_{b n} / b h^{2} R_{b t}=c \lambda[m \lambda-n(0.5-\xi)]+ \\
+y \alpha \mu \psi_{b s}(\bar{h}-\xi)(\bar{h}-0.5) / \lambda+0.5 y(0.5-\xi / 3) \xi^{2} / \lambda .
\end{gathered}
$$

Here $L$ is the dimensionless total external moment.

It is possible to determine the moment upon reaching at which a crack propagates from the system (13). If the crack propagates, then, in this case, $R_{b t}$ is equal to $\sigma_{m}, c=0.909$, $y=2.4, n=0.683, m=0.418$. 
Now, taking into account from (12) that $\lambda=1-z-\xi$, the first equation of the system (13) can be written in this form:

$$
0.256(1-z)^{2}-0.512(1-z) \xi-0.244 \xi^{2}+\alpha \mu \psi_{b s}(\bar{h}-\xi)=0 .
$$

Equation (14) is a quadratic equation for the dimensionless height of the compressed zone $\xi$. The solution of Equation (14) is:

$$
\begin{gathered}
\xi=-P \pm \sqrt{P^{2}+q}, \\
\text { where } P=1.049(1-z)+2.049 \alpha \mu \psi_{b s}, \\
q=1.049(1-z)^{2}+4.098 \alpha \mu \psi_{b s} \bar{h} .
\end{gathered}
$$

Further, from the second equation of system (13), the moment of crack propagation is found

$$
\begin{aligned}
& L_{m}=M_{m} / b h^{2} R_{b t}=0.418 \lambda^{2}-0.683 \lambda(0.5-\xi)+ \\
& +\left[2.667 \alpha \mu \psi_{b s}(\bar{h}-\xi)(\bar{h}-0.5)+0.667(1-\xi) \xi^{2}\right] / \lambda
\end{aligned}
$$

The system (13) solution is greatly simplified if the dependence of the dimensionless stress at the crack tip $c$ on the dimensionless load parameter $L$ is precalculated for a known relative crack length $z$. The first equation of system (13) is a quadratic equation concerning the height of the compressed zone $\xi$. The parameter $\xi$ is determined from this equation by setting the dimensionless stress $c$. After substitution into the second equation of system (13), the dimensionless moment $L$ is found, which corresponds to the given stress.

Calculations of the dependence of the dimensionless stress at the crack tip $c$ on the dimensionless load parameter $L$ are easily programmable. For example, Figure 3 shows such dependence for the different relative crack length $z$.

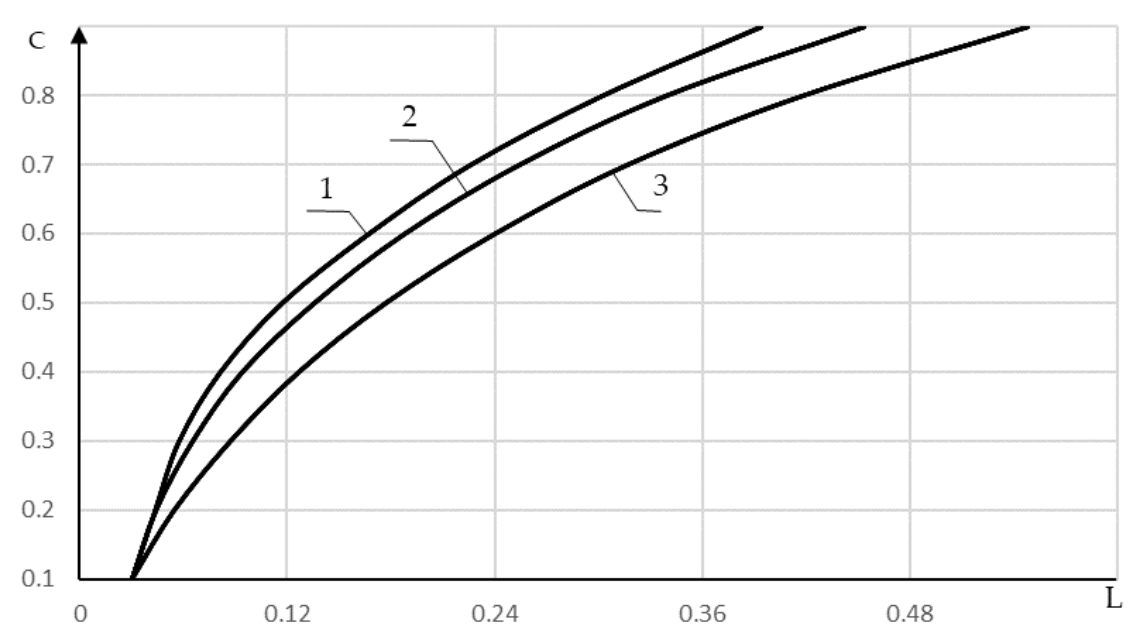

Figure 3. Dependence of dimensionless stress $c$ at the crack tip $c$ on the dimensionless moment $L: 1$ of $z=0.1 ; 2$ of $z=0.2 ; 3$ of $z=0.3$.

The sequencing for determining the maximum compressive stresses and the stresses in reinforcement from a known external bending moment $M$ is as follows:

- $\quad$ finding the dimensionless moment $L$ from the Equation (16);

- finding the dimensionless stress at the crack tip $c$ from the dimensionless load parameter $L$ at a known relative crack length $z$ (Figure 3);

- $\quad$ finding $\xi$ from the Equation (15);

- $\quad$ and then we determine $\lambda$ from $\xi$ using (12).

And then, using Formulas (5) and (6), the maximum compressive stresses in concrete and the stresses in reinforcement are determined. 
Figure 4 shows the relative height of the stretched zone (tension side) $\lambda$ on the parameter $c$ obtained during the calculation of the previous graph. This relationship is useful both for determining stresses and for calculating SIF later on.

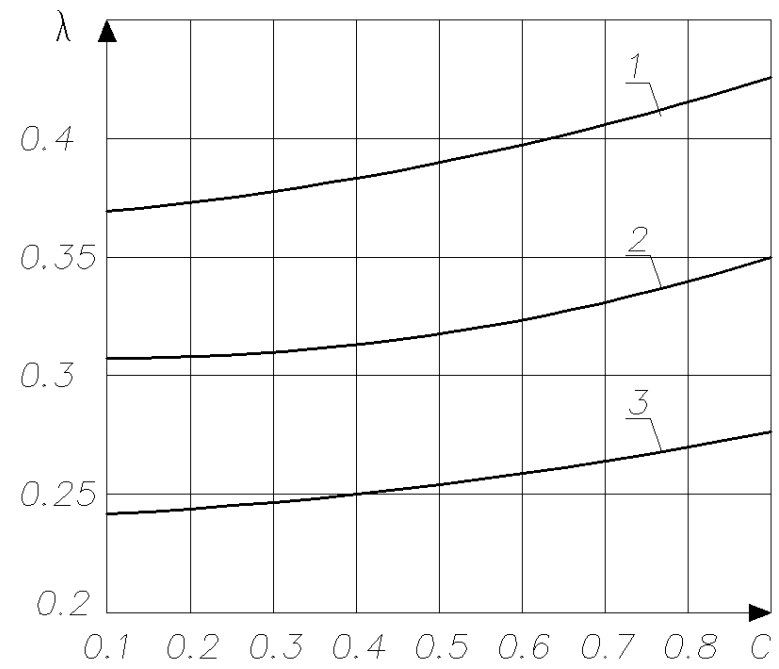

Figure 4. Dependence of the tension side height $\lambda$ on the stress at the crack tip $c$ : 1 on $z=0.1 ; 2$ on $z=0.2 ; 3$ on $z=0.3$.

Such a solution to system (13) is valid as long as the nominal stress $\sigma_{m}$ is less than or equal to the tensile strength of concrete $R_{b t}$. Otherwise, the initial crack length will increase. The new crack length, corresponding to the effective moment $M>M_{m}$, is also determined from the system (13) at $\sigma_{m}=R_{b t}$. To determine the stresses by Formulas (5) and (6) and calculate the SIF, it is sufficient to determine the dimensionless parameters $\xi$ and $\lambda$ from this system.

The compressive stress epure should also be considered nonlinear and described by expression (2) to obtain more accurate results in the crack propagation case. The resultant internal forces in the compressed zone and their moment relative to the zero line will be found by integrating over the zone height. The stress state parameters' calculations show that replacing a linear epure of compressive stresses with a nonlinear one does not introduce significant refinements into the system (13) solution if the maximum compressive stress $\sigma_{\mathrm{b}}$ does not exceed $70 \%$ standard resistance $R_{b n}$.

At high compressive stresses $\left(\sigma_{b}>0.7 R_{b n}\right)$, this epure can be taken as rectangular, taking into account the completeness coefficient of the epure $\omega$ (Figure 1c). In this case, in the formulas for stresses (5) and (6), expression 1.1y will be a constant value equal to 2.667. Then the equilibrium Equations (9) and (10) for a section of the general form will be rewritten as follows:

$$
\begin{gathered}
N_{p}+\sigma_{s} A_{s}-\omega \sigma_{b}\left(b x+A_{c}\right)+\sigma_{s}^{\prime} A_{s}^{\prime}=0 \\
M_{p c}+\sigma_{s} A_{s}(h / 2-a)+0.5 \omega \sigma_{b}\left[b x(h-x)+A_{c}\left(h-h_{c}\right)\right]- \\
-\sigma_{s}^{\prime} A_{s}^{\prime}\left(h / 2-a^{\prime}\right)+2.667 \alpha R_{b t} A_{s}^{\prime}\left(x-a^{\prime}\right)\left(h / 2-a^{\prime}\right) / z_{p}=M_{b n} .
\end{gathered}
$$

Equation (17) is also valid for propagating cracks.

For a reinforced concrete rectangular beam, Equation (17) can be rewritten in the dimensionless form:

$$
\begin{gathered}
0.256 \lambda^{2}-0.5 \xi^{2}+\alpha \mu \psi_{b s}(\bar{h}-\xi)=0 . \\
M_{b n} / b h^{2} R_{b t}=0.44 \lambda^{2}-0.717 \lambda(0.5-\xi)+ \\
+2.8 \alpha \mu \psi_{b s}(\bar{h}-\xi)(\bar{h}-0.5) / \lambda+0.7(1-\xi) \xi^{2} / \lambda .
\end{gathered}
$$


In this system of nonlinear Equation (18), the dimensionless parameters $\xi$ and $\lambda\left(x, z_{p}\right)$ are determined.

\subsection{Determination of the Stress Intensity Factor}

Let us determine the SIF at the crack tip $K_{I}$. The crack tip is a strong stress concentrator. According to the linear theory of elasticity [32], the stress there is determined by the formula

$$
\sigma_{\theta}=K_{I} / \sqrt{2 \pi r}
$$

where $r$ is the distance from the crack tip to the point under consideration.

The definition of SIF is based on the equality of the longitudinal forces at the crack tip with and without stress concentration. Local stresses are determined by Formula (19) and nominal stresses are determined by Formula (6).

Let us determine the length of the stress concentration zone $d$ from the condition of equality of the nominal and local stresses at the end of this zone (Figure 1d). The nominal stresses at distance $d$ from the crack tip are

$$
\sigma_{n}=1.1 R_{b t}\left[1-(1-c)^{1-t}\right], \quad t=d / z_{p}
$$

Longitudinal forces per unit beam's width in the concentration zone are

$$
I_{1}=\int_{0}^{d} \sigma_{\theta} d r=K_{I} \sqrt{2 d / \pi}=K_{I}^{2} / \pi \sigma_{n} .
$$
tion are

Longitudinal forces in the same zone without taking into account the stress concentra-

$$
I_{2}=\int_{z_{p}-d}^{z_{p}} \sigma d z=1.1 R_{b t} z_{p}\left\{t+\left[1-c-(1-c)^{1-t}\right] / y\right\} .
$$

Equating these forces $I_{1}=I_{2}$, we get

$$
f(t)=t-(1-c)^{1-t}(2 t-1 / y)-(1-c) / y=0 .
$$

Solving this equation with a known value $c(y)$, we find the parameter $t$. Figure 5 shows the dependence of this parameter on the stress at the crack tip.

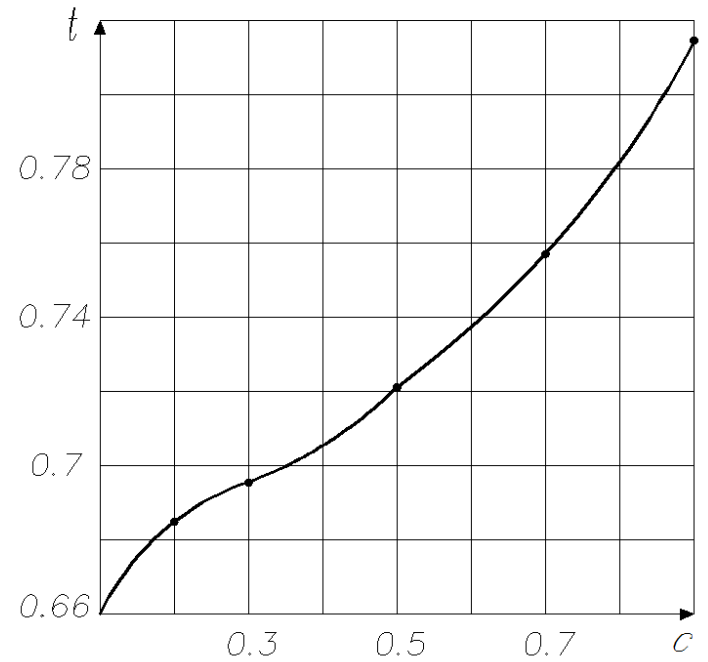

Figure 5. The dependence of parameter $t$ on the stress at the dimensionless stress at the crack tip $c$.

Further, from (19), we find the SIF 


$$
\begin{gathered}
K_{I}=\sqrt{2 \pi d} \cdot \sigma_{n}=\sqrt{2 \pi} \cdot 1.1 R_{b t}\left[1-(1-c)^{1-t}\right] \sqrt{t \lambda h} . \\
\sigma_{m}=R_{b t}, \quad c=0.909, \quad t=0.808
\end{gathered}
$$

If the external moment $M$ is greater than $M_{m}$, then

$$
K_{I}=0.914 R_{b t} \sqrt{z_{p}} .
$$

\subsection{Calculation Example}

The design ratios set out in Sections 3.1 and 3.2 represent the proposed calculation method. This subsection provides an example of a calculation.

Calculations show that the SIF decreases to zero with increasing crack length. The decrease is because during bending, there is necessarily a minimum zone of compressive stresses. As the crack length grows, this zone's presence reduces the length of the tensile stress zone to zero. When tensile forces are perceived only by the reinforcement, the crack does not develop. In this case, the SIF becomes zero. Moreover, the destruction of the beam occurs not due to an increase in the crack length but due to the achievement of the yield strength by the stress in the reinforcement or due to crushing of the concrete in the compressed zone when the stress reaches the ultimate strength.

The dependence of the SIF on the external moment is analyzed by using system (13) and expression (24). The calculations were carried out for a rectangular 2-m long beam with a size of $15 \times 30 \mathrm{~cm}$ made of $\mathrm{B} 25$ grade concrete $\left(R_{b}=1.6 \mathrm{MPa}, R_{b}=14.5 \mathrm{MPa}\right)$ with reinforcement made of AIII steel (design resistance $R_{s}=370 \mathrm{MPa}, \alpha \mu \psi_{b s}=0.15$ ). The beam length is not directly used in the calculation. Instead, the calculation uses the moment in the section with a crack. The beam has an initial crack $l_{0} 6 \mathrm{~cm}$ long. For this case, the crack growth moment is determined from expression (16) and is equal to $M_{m}=9.96 \mathrm{kN} \cdot \mathrm{m}$. Figure 6 shows the calculation results.

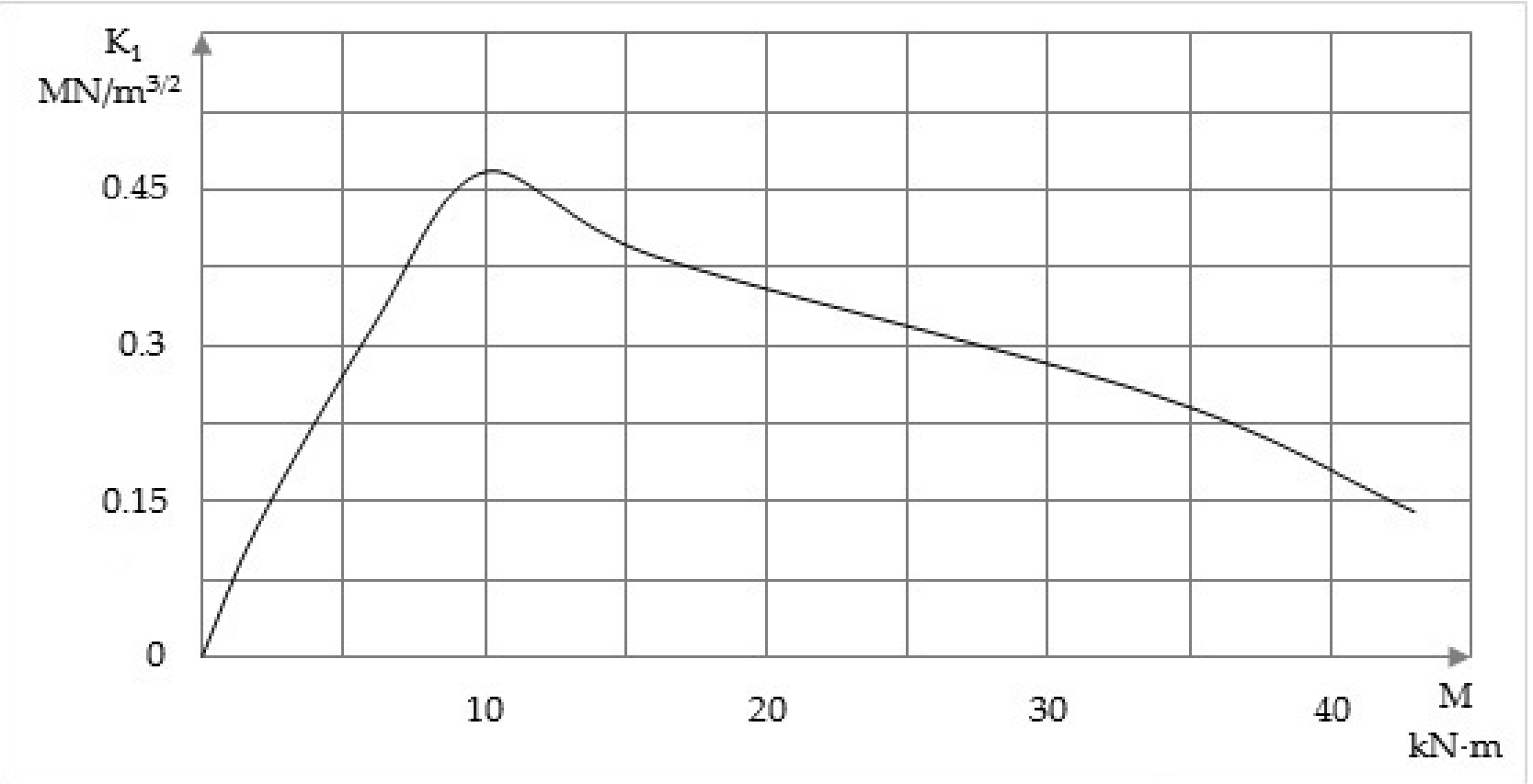

Figure 6. Change in SIF from external moment.

Figure 6 shows that at $M<M_{m}$, the SIF grows with the increasing external moment, but nonlinearly. The SIF growth rate is less than with a linear calculation. At $M>M_{m}$, crack propagation occurs and the SIF decreases with an increase in the external moment 
M. Similar calculations for the same beam without an initial crack show that the same dependence of the SIF on the external moment is observed for growing cracks.

If for a known crack length and a given external moment, the SIF becomes less than the limiting value for a given material, then stable crack propagation occurs. For the concrete under consideration, it is approximately equal to $0.42 \mathrm{MN} / \mathrm{m}^{3 / 2}$. That is, until the moment when $M=8.2 \mathrm{kN} \cdot \mathrm{m}$, the crack will propagate steadily. If the crack is unstable, rapid crack propagation is possible with a slight increase in the external moment. The growth of the crack length continues until the SIF decreases to a value. This SIF value corresponds to a certain value of the crack length, which is determined from system (13) or (18) and expression (24).

The stress value in the reinforcement (6) estimates the beam's load-bearing capacity and the maximum compressive stress in the concrete (5). Parameters found for the initial or growing length of the crack are substituted into these formulas.

At the end of the calculations' examples, the following should be noted. The method proposed in this article in Sections 3.1 and 3.2 is still the only analytical method for determining the SIF in bent reinforced concrete beams.

The method is approximate since the determination of the size of the stress concentration zone does not have a rigorous mathematical formulation. The derivation of Formula (24) for the SIF is based on the assumption that the size of the stress concentration zone at the crack tip is determined by the equality of the nominal and local stresses at the end of this zone (Figure 1d).

In [33], a similar approach was used to determine the SIFs in various fractured plane problems with an exact solution. The author concluded that the error of the method does not exceed $20 \%$ in the direction of decreasing SIF.

\subsection{Numerical Calculation}

This study also performed calculations to determine the SIF by the finite element method, as described in Section 2.2. To carry out these calculations, it is necessary to know the length of the crack. This calculation is possible for an initial non-propagating crack. For propagating cracks, in the general case, it must be preliminarily determined depending on the external moment based on a nonlinear calculation of the stress-strain state. In this case, three-dimensional beam or volumetric elements should be used, which have additional options that exclude destroyed elements from the calculation. The specifics of calculating reinforced concrete beams by the finite element method are described in [34].

The calculation of the above-considered reinforced concrete beam with an initial crack under the action of a moment of $6 \mathrm{kN} \cdot \mathrm{m}$ was carried out (Figure 7).

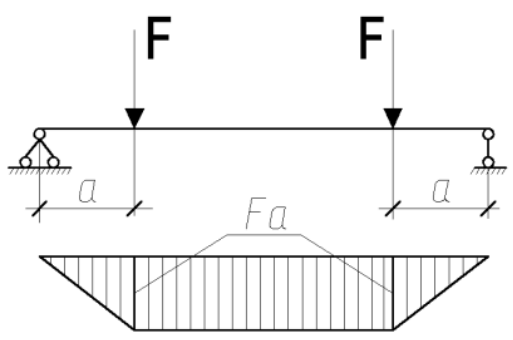

Figure 7. The 2-m long beam calculation scheme with a moment diagram The distance $a$ is $0.4 \mathrm{~m}$.

A 2- $\mathrm{m}$ long beam is hinged at the ends and loaded at the same distance of $0.4 \mathrm{~m}$ from the supports by equal shear forces (Figure 7). Then a state of pure bending arises between the points of forces' application. The magnitude of the moment depends on the magnitude of the applied forces. The calculations assumed that the modulus of elasticity of concrete was $E_{b}=24,000 \mathrm{MPa}$ and the cross-sectional area of the reinforcement was $A_{s}=6.75 \mathrm{~cm}^{2}$ $(\mu=1.5 \%)$.

The beam was split into 1,762,663 finite elements with 2,387,736 nodes. The characteristic dimension of the end element was $5 \mathrm{~mm}$. As a result of the calculation, the SIF was 
$K_{I}=0.321 \mathrm{MN} / \mathrm{m}^{3 / 2}$, which differs from the analytical calculation by only $1.3 \%$. As the bending moment increases, the SIF increases linearly, which leads to an increase in the discrepancy between the results. Thus, under the action of a bending moment of $10 \mathrm{kN} \cdot \mathrm{m}$, the SIF is equal to $0.466 \mathrm{MN} / \mathrm{m}^{3 / 2}$ and the discrepancy with the analytical solution is $12.4 \%$. This discrepancy is a consequence of the linear approach in the numerical calculation of SIF. With a further increase in the bending moment, the results become incomparable due to the increase in the initial crack length.

Now the SIF could be analytically calculated for the same beam under the action of a moment of $16 \mathrm{kN} \cdot \mathrm{m}$, considering the crack length determined by the above method (Sections 3.1 and 3.2). From system (18), we find $\xi=0.418, \lambda=0.232$. Then the crack length.

$$
l=h(1-\xi-\lambda)=10.5 \mathrm{sm} .
$$

The SIF calculation by the finite element method gives $K_{I}=0.533 \mathrm{MN} / \mathrm{m}^{3 / 2}$ and the discrepancy with the analytical solution given in Figure 6 is $20.8 \%$.

These calculations show that for bending reinforced concrete beams, the error in determining SIF by the finite element method increases with an increase in the bending moment. This increase is due to the growing influence of physical nonlinearity at high stresses. Under these conditions, it is recommended to calculate the SIF only by the analytical method.

Some preliminary partial results of this study were reported at an international conference [35] and received the participants' approval.

\section{Conclusions}

The study determined the stress state of reinforced concrete beams with an initial and growing crack. For beams with an initial crack, the value of the external moment is determined, above which the crack length increases. If this moment is exceeded, then a growing crack appears. The length of the growing crack is determined by calculating the stress state along with the maximum compressive stress in concrete and stress in reinforcement. These calculations make it possible to assess the bearing capacity of cracked reinforced concrete beams.

The stress intensity factor (SIF) is used to assess the beam's fracture toughness based on the strength criterion of fracture mechanics. SIF at the crack tip is determined analytically by analyzing the stress state in the crack zone. In addition, the influence of the crack length and external moment on the SIF value is analyzed. The paper also compares the results obtained by analytical and numerical methods.

Based on the results of the work, the following conclusions can be drawn.

1. The analytical method for determining the stress intensity factor (SIF) with an initial and growing crack in bent reinforced concrete beams is proposed. The method is based on the assumption that the size of the stress concentration zone at the crack tip is determined by the equality of the nominal and local stresses at the end of this zone (Figure 1d). The method determines the value of the external moment starting from which the crack length increases.

2. The results obtained make it possible to assess the bearing capacity of reinforced concrete beams with a crack and assess the crack resistance of the beam by the force criterion of fracture mechanics. The analytical calculation method is valid for beams of arbitrary cross-sections, but explicit dependencies and numerical results are given for rectangular cross-section beams, which are most often used. Numerical calculation of SIF is recommended for non-growing initial cracks or a low-stress level if the maximum compressive stresses in concrete do not exceed $70 \%$ of the ultimate compressive strength.

3. The same problem is solved in a three-dimensional formulation by the FE method, considering the stress field's peculiarities at the crack tip. The calculation results coincide with the analytical solutions. 
4. It was found that SIF decreases with increasing crack length in a reinforced concrete beam. Consequently, unstable crack propagation reduces its bearing capacity but does not lead to rapid beam destruction.

Author Contributions: Conceptualization, Z.S.N.; methodology, Z.S.N., O.K. and Z.B.B.; validation, O.K.; formal analysis, Z.S.N. and M.Z.B.; investigation, I.A.K. and D.T.T.; writing-original draft preparation, Z.S.N.; writing—review and editing, N.I.V.; visualization, O.K.; project administration, Z.S.N.; funding acquisition, N.I.V. All authors have read and agreed to the published version of the manuscript.

Funding: The research is partially funded by the Ministry of Science and Higher Education of the Russian Federation as part of the World-Class Research Center Program: Advanced Digital Technologies (contract No. 075-15-2020-934 dated 17.11.2020).

Institutional Review Board Statement: Not applicable.

Informed Consent Statement: Not applicable.

Conflicts of Interest: The authors declare no conflict of interest. The funders had no role in the design of the study; in the collection, analyses, or interpretation of data; in the writing of the manuscript, or in the decision to publish the results.

\section{References}

1. Kodysh, E.N.; Nikitin, I.K.; Trekin, N.N. Calculation of Reinforced Concrete Structures from Heavy Concrete for Strength, Crack Resistance and Deformation; Association of Civil Engineering Universities: Moscow, Russia, 2011, ISBN 978-5-93093-723-7.

2. Korgin, A.V.; Zeyd, K.L.Z.; Ermakov, V.A. Healthmonitoring of building constructions with crack-like defects. Vestn. MGSU 2013, 77-83. [CrossRef]

3. Ckhum, A. Experimental investigation of deflected mode of the rienforced concrete beams with organized cracks under long-term loading. Vestn. SibADI 2018, 15, 606-616. [CrossRef]

4. Mitasov, V.M.; Statsenko, N.V.; Sametov, F.K.; Kurbonov, A.M. Crack strength of hollow core slabs: Experimental research. Russ. Automob. Highw. Ind. J. 2019, 16, 366-377. [CrossRef]

5. Fantilli, A.P.; Chiaia, B. Golden Ratio in the Crack Pattern of Reinforced Concrete Structures. J. Eng. Mech. 2013, 139, 1178-1184. [CrossRef]

6. Bykov, A.A.; Matveenko, V.P.; Shardakov, I.N.; Shestakov, A.P. Shock wave method for monitoring crack repair processes in reinforced concrete structures. Mech. Solids 2017, 52, 378-383. [CrossRef]

7. Chernin, L.; Val, D.V. Prediction of corrosion-induced cover cracking in reinforced concrete structures. Constr. Build. Mater. 2011, 25, 1854-1869. [CrossRef]

8. Hsu, T.T.C. Unified Theory of Reinforced Concrete; CRC Press: Boca Raton, FL, USA, 2017, ISBN 9781351406109.

9. Bazant, Z.P. Mechanics of Fracture and Progressive Cracking in Concrete Structures; Martinus Nijhoff Publishers: Leiden, Belgium, 1985, ISBN 9024729602.

10. Demyanov, A.I.; Naumov, N.V.; Kolchunov, V.I. The calculating method of crack resistance and rigidity of reinforced concrete composite constructions under the action torsion with bending. Build. Reconstr. 2018, 3-19. [CrossRef]

11. Nuguzhinov, Z.; Vatin, N.; Bakirov, Z.; Khabidolda, O.; Zholmagambetov, S.; Kurokhtina, I. Stress-strain state of bending reinforced beams with cracks. Mag. Civ. Eng. 2020, 97. [CrossRef]

12. Tay, Y.W.D.; Qian, Y.; Tan, M.J. Printability region for 3D concrete printing using slump and slump flow test. Compos. Part B Eng. 2019, 174, 106968. [CrossRef]

13. Kaklauskas, G. Crack Model for RC Members Based on Compatibility of Stress-Transfer and Mean-Strain Approaches. J. Struct. Eng. 2017, 143, 04017105. [CrossRef]

14. Ma, F.J.; Kwan, A.K.H. Crack width analysis of reinforced concrete members under flexure by finite element method and crack queuing algorithm. Eng. Struct. 2015, 105, 209-219. [CrossRef]

15. Kwan, A.K.H.; Ma, F.J. Crack width analysis of reinforced concrete under direct tension by finite element method and crack queuing algorithm. Eng. Struct. 2016, 126, 618-627. [CrossRef]

16. Barre, F.; Bisch, P.; Chauvel, D.; Cortade, J.; Coste, J.F.; Dubois, J.P.; Erlicher, S.; Gallitre, E.; Labbé, P.; Mazars, J.; et al. Control of Cracking in Reinforced Concrete Structures; Wiley Blackwell: Hoboken, NJ, USA, 2016, ISBN 9781119347088.

17. Oliver-Leblond, C.; Delaplace, A.; Ragueneau, F. Modelling of three-dimensional crack patterns in deep reinforced concrete structures. Eng. Struct. 2015, 83, 176-186. [CrossRef]

18. Shiu, W.; Donzé, F.V.; Daudeville, L. Discrete element modelling of missile impacts on a reinforced concrete target. Int. J. Comput. Appl. Technol. 2009, 34, 33-41. [CrossRef]

19. Yang, S.T.; Li, K.F.; Li, C.Q. Numerical determination of concrete crack width for corrosion-affected concrete structures. Comput. Struct. 2018, 207, 75-82. [CrossRef] 
20. Iakovenko, I.A.; Kolchunov, V.I. The development of fracture mechanics hypotheses applicable to the calculation of reinforced concrete structures for the second group of limit states. J. Appl. Eng. Sci. 2017, 15, 371-380. [CrossRef]

21. García-Álvarez, V.O.; Gettu, R.; Carol, I. Analysis of mixed-mode fracture in concrete using interface elements and a cohesive crack model. Sadhana 2012, 37, 187-205. [CrossRef]

22. Anderson, T.L. Fracture Mechanics: Fundamentals and Applications, 4th ed.; CRC Press: Boca Raton, FL, USA, 2017, ISBN 9781498728133.

23. Malipatil, K.M.; Itti, S.V. Stress Intensity Factor and Damage Index of Reinforced Concrete Beam. In Fatigue, Durability, and Fracture Mechanics; Lecture Notes in Mechanical Engineering; Springer Science and Business Media Deutschland GmbH: Berlin/Heidelberg, Germany, 2021; pp. 305-316.

24. Kosior-Kazberuk, M.; Berkowski, P. Fracture Mechanics Parameters of Fine Grained Concrete with Polypropylene Fibres. In Proceedings of the Procedia Engineering; Elsevier Ltd.: Amsterdam, The Netherlands, 2016; Volume 161, pp. $157-162$.

25. Wang, Z.; Gou, J.; Gao, D. Experimental study on the fracture parameters of concrete. Materials 2021, 14, 129. [CrossRef]

26. Gomes, R.F.; Dias, D.P.; Silva, F.d.A. Determination of the fracture parameters of steel fiber-reinforced geopolymer concrete. Theor. Appl. Fract. Mech. 2020, 107, 102568. [CrossRef]

27. Jenq, Y.; Shah, S.P. Two Parameter Fracture Model for Concrete. J. Eng. Mech. 1985, 111, 1227-1241. [CrossRef]

28. Carpinteri, A.; Spagnoli, A. A fractal analysis of size effect on fatigue crack growth. Int. J. Fatigue 2004, 26, 125-133. [CrossRef]

29. Kolchunov, V.I.; Dem'yanov, A.I. The modeling method of discrete cracks in reinforced concrete under the torsion with bending. Mag. Civ. Eng. 2018, 81, 160-173. [CrossRef]

30. Karpenko, N.I. General Models of Reinforced Concrete Mechanics; Stroyizdat: Moscow, Russia, 1996.

31. Nuguzhinov, Z.S. The Theory of Calculation of Damaged Reinforced Concrete Structures; Publishing House of KSTU: Karaganda, Kazakhstan, 2012.

32. Elliott, K.S. Precast Concrete Structures, 2nd ed.; CRC Press: Boca Raton, FL, USA, 2016, ISBN 9781498724005.

33. Wittmann, F.H.; Zaytsev, Y.V. Application of fracture mechanics to investigate durability of concrete under load. In Proceedings of the 8th International Conference on Fracture Mechanics of Concrete and Concrete Structures, FraMCoS 2013, Toledo, Spain, 10-14 March 2013; pp. 50-56.

34. Ercolani, G.D.; Ortega, N.F.; Felix, D.H. Diagnosis of failures in concrete structures. In Concrete and Concrete Structures: A Review and Directions for Research; Nova Science Publishers, Inc.: New York, NY, USA, 2017; pp. 43-84, ISBN 9781536127966.

35. Nuguzhinov, Z.S.; Bakirov, Z.B.; Yu Kurokhtin, A.; Khabidolda, O.; Nuguzhinova, A. Assessment of Bending Reinforced Concrete Beams Crack Resistance. IOP Conf. Ser. Mater. Sci. Eng. 2019, 690, 012002. [CrossRef] 